\title{
Digital Assignments: \\ The Importance Of Pedagogical Context
}

S. Christoffersen, Philadelphia University, USA

E. Granitz, Long Island University, USA

\begin{abstract}
We assess students' appreciation and use of various tools designed to extend effective learning beyond the classroom. For a given tool, results vary depending upon the overall pedagogical approach of the course.
\end{abstract}

\section{INTRODUCTION}

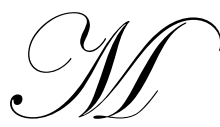

otivating student interest is one of the most difficult challenges for educators today, especially when it entails time outside of the classroom. This paper suggests that high technology components can enhance student engagement but that the effectiveness of a given high technology component is dependent on the overall learning environment, specifically the degree to which technology is integrated throughout the course.

We examine two Principles of Microeconomics course models. One is a traditional course with a textbook, midterm exams and a final exam; the students meet in the classroom on a regular schedule, read a paper textbook and use pencils for problem solving. In the high tech model, the students still meet for the regular hours each week but the textbook and study tools are all online (students are encouraged to purchase an unembellished hard copy of the online textbook).

We introduce the same web based exercises to both course types. We then assess the usefulness of the given exercises and the impact of the overall course structure. In addition, we examine the students' responses to other aspects of the course, given the different approaches.

\section{TWO LEARNING ENVIRONMENTS}

In general, a student is exposed to material by three main conduits: the student is asked to listen to lectures, read subject matter, and solve assigned problems. In both courses in this study, the students are expected to read a textbook and complete assigned homework. In the traditional course, the students have a study guide to stimulate learning outside of the classroom. In the high tech course the students are required to complete an open book online quiz prior to class. The purpose of the quiz is to force the students to read the online book and think about the material before they attend the lecture.

In the high tech course, the study guide materials are all online including flash cards, matching and some graphing exercises. There are also numerical supply and demand problems online which have answers available for practice, and mimic the online quiz, the results of which are reported to the instructor. In addition to these relatively standard ancillaries, the instructor has created a number of online Flash based problems such as graphical supply and demand problems, graphical industry models, and numerical and graphical trade problems. Only the publisher's quizzes are specifically assigned as homework to be graded as the correct completion rates of the newly created problems can not be tracked. The students are strongly recommended to use the instructor's practice problems as they mimic the types of problems and graphs they must answer on their in class exams. The technology aspects of the course extend into the classroom where the lecture/discussion is supported by the use of a tablet PC with a projector and an internet connection. 
Both instructors use a lecture / discussion format in the classroom. Both classes have the students do some group problem solving in class as well. Such collaborative problem-solving in class addresses diverse learning styles and allows earlier assessment of the students' strengths and weaknesses. The high tech course is designed to encourage active learning outside the classroom through the discipline imposed by the online quizzes. The traditional class regularly incorporates active learning exercises throughout the semester, fostering more experiential learning opportunities in the classroom. Both efforts are geared to the same goal, engaging students in the learning process.

\section{LITERATURE ON PEDAGOGY}

The effectiveness of active learning is supported by a large body of literature (Cross, 1987). Economics, in particular, "requires active participation by students" according to Siegfried, et al., (1991). Hansen, Salemi, and Siegfried (2001) stress the need to change the methods that we use to teach the principles of economics classes; despite continuing pressure to improve pedagogy, Becker and Watts (1996) find that active learning is not used in the majority of introductory courses. This may be because the costs to the instructor of changing teaching techniques may outweigh the benefits. "There is a considerable cost in changing the manner in which we teach and the incentives to change how we teach do not exist in most institutions." (Buckles, 2001, p.2) Furthermore, costs of innovative pedagogy can include heightened career risk. In surveys, students' responses to innovative pedagogy include dubious comments such as they are not "used to it" and prefer fewer resources. While this may not be a majority opinion nor an accurate assessment of the value of the pedagogy, negative student comments can be costly to an instructor.

One indicator of the potential cost to a faculty member for implementing innovative pedagogy is the initial student response found in the high tech course: a high drop rate at the onset of the course. Some students will be frustrated with the set up costs of using the technology. Some students will decide that taking weekly quizzes, in addition to their other work, is too demanding. Furthermore, to take the online quizzes, the students have to read the text and/or look for the answers and try and solve the problems posed. The expectation is that students will grasp the definitions and then contemplate the problems for each chapter. These activities required active thoughtful learning on the part of the students. The problem arises because the quizzes are immediately graded and diligent students, just working from the text with no additional explanations, often earn grades between $50 \%$ and $70 \%$. As explained to the students, grades in this range or above would be good scores. Not all students clearly understand how the quizzes are curved and so some drop the course early in the semester thinking they did not adequately understand the material. This higher drop rate may be an issue to probationary faculty in particular.

Under the umbrella of active learning is collaborative learning: "the instructional use of small groups" (Johnson et al. (1991). Collaborative learning is particularly important for the more diverse class. Lage and Treglia (1998, p.42) state that "Cooperative learning, .....and other forms of nonhierarchical classroom activities ..... offer possibilities for enhancing the persistence of women in economics as well as leading to improved performance for students with diverse learning styles." The diversity of learning styles is described in research showing "60\% of American students are visual dominant learners, 37\% are auditory dominant learners, and 3\% are kinesthetic dominant learners" (Rogers, 2000, p.20). The traditional course relies more on collaborative learning and activities in the classroom while the high tech course relies on the visual online experience outside of the classroom and enhanced discussion in the class.

Literature shows that active and collaborative learning strategies enhance retention and understanding of complex concepts. The challenges facing today's students require them to acquire skills more profound than simple memorization. "Now the real world demands individuals use high order reasoning skills to solve complex problems..... Learners must now be viewed as proactive participants in learning, actively seeking ways to analyze, question, interpret, and understand their ever-changing environment" (Newby et. al., p.6, emphasis added).

Collaborative learning is more effective when done regularly. In courses where the students don't routinely work together, they militate when occasionally requested to form groups and work together. In the "traditional" classroom described in this paper, the students form groups to conduct exercises or solve problems regularly, 
beginning with the first class meeting. As the semester progresses, the students readily work together and do not need urging to get results; this would not be the case in a classroom where students generally sit passively and listen to the lecture. In the same way, the high tech exercises are better received by the students in the more consistently high tech learning environment, as shown by the survey results that follow. Learning is enhanced by immediate feedback; the traditional classroom has collaborative feedback in real time, the high tech has immediate online feedback. Despite their differences, both pedagogies embrace student centered learning and improved motivation. Both are effective in sundry ways.

\section{ASSESSMENT}

Learning theorists have long told us the extreme importance of motivation.” (Buckles, 1998, p.227, emphasis added). Going as far back as ancient Rome, the poet, Horace, wrote "Instruct by pleasing". That active learning leads to a positive perception is described by Light (1990), "Active engagement with other learners is a characteristic of educational experiences that are highly personally fulfilling." Vail (1994) discusses the importance of a positive attitude in her book, Emotion: the On/Off Switch for Learning. While learning outcomes remain difficult to assess, students' attitudes are readily surveyed. We use such surveys to initially indicate the effectiveness of the pedagogies we introduced to the different class types.

Survey data of the classes show the students' levels of receptiveness to various aspects of both courses. The surveys were distributed in the last week of classes, 54 students returned the survey in the traditional course and 33 in the high tech course. The survey questions are presented below with the tabulated responses.

\section{Assessment Of Teaching Tools Survey Results:}

The first major difference between the two courses is the percent of students who read the textbook whether online or the hard copy. Overall we see that $85 \%$ of the high tech students read the book compared to $62 \%$ in the traditional course.

Table 1

\begin{tabular}{|l|l|l|l|l|l|c|c|c|}
\hline & \multicolumn{3}{|c|}{ Traditional High Tech } \\
\hline & Yes & No & Yes & No & Yes & No & Yes & No \\
\hline Did you read the textbook? & $\mathbf{3 3}$ & $\mathbf{2 0}$ & $\mathbf{6 2 \%}$ & $\mathbf{3 8 \%}$ & $\mathbf{2 8}$ & $\mathbf{5}$ & $\mathbf{8 5 \%}$ & $\mathbf{1 5 \%}$ \\
\hline $\begin{array}{l}\text { Do you think the textbook helped you to participate } \\
\text { more in class? }\end{array}$ & 12 & 39 & $24 \%$ & $76 \%$ & 14 & 18 & $44 \%$ & $56 \%$ \\
\hline $\begin{array}{l}\text { Do you think the textbook helped you perform better on } \\
\text { tests? }\end{array}$ & 21 & 28 & $43 \%$ & $57 \%$ & 8 & 23 & $26 \%$ & $74 \%$ \\
\hline
\end{tabular}

As the table below shows, $57 \%$ of the high tech students read all or most of the assigned chapters compared to only $30 \%$ in the traditional class. In both courses, about a quarter of the students didn't try to read the book or got discouraged.

Table 2

\begin{tabular}{|l|c|c|c|c|}
\hline I read the book (circle one answer) & \multicolumn{2}{|c|}{ Traditional } & \multicolumn{2}{c|}{ High Tech } \\
\hline a. All of the assigned chapters & 2 & $\mathbf{4 \%}$ & 10 & $\mathbf{3 0 \%}$ \\
\hline b. most of the assigned chapters & 14 & $\mathbf{2 6 \%}$ & 9 & $\mathbf{2 7 \%}$ \\
\hline c. skimmed the assigned chapters & 23 & $43 \%$ & 6 & $18 \%$ \\
\hline d. tried to read but got discouraged & 12 & $22 \%$ & 5 & $15 \%$ \\
\hline e. did not buy the book & 3 & $6 \%$ & 3 & $9 \%$ \\
\hline & 54 & & 33 & \\
\hline
\end{tabular}


Examining the students' motivation for reading the text we can see that the high tech students were largely motivated by the required chapter quizzes. The traditional students are also motivated by the "quizzes" but for this course those occur infrequently: two midterms and the final.

\section{Table 3}

\begin{tabular}{|c|c|c|c|c|}
\hline If you read the textbook what motivated you to do so? & \multicolumn{2}{|c|}{ Traditional } & \multicolumn{2}{|c|}{ High Tech } \\
\hline a. Better prepared for class & 11 & $24 \%$ & 2 & $7 \%$ \\
\hline b. Answer Quizzes & 15 & $33 \%$ & 22 & $79 \%$ \\
\hline c. Facilitates learning the material & 9 & $20 \%$ & 1 & $4 \%$ \\
\hline d. Figure out what the instructor said in class & 10 & $22 \%$ & 3 & $11 \%$ \\
\hline & 45 & & 28 & \\
\hline
\end{tabular}

The real impact of the online quizzes can be seen in the timing of the students' reading. Of the high tech students 93\% (before and both) tended to read the material before class. The traditional students only 35\% read the book before class.

Table 4

\begin{tabular}{|l|c|c|c|c|}
\hline If you read the textbook did you read it before class or after? & \multicolumn{2}{|c|}{ Traditional } & \multicolumn{2}{|c|}{ High Tech } \\
\hline a. Before & $\mathbf{1 7}$ & $\mathbf{3 5 \%}$ & $\mathbf{2 5}$ & $\mathbf{8 3 \%}$ \\
\hline b. After & $\mathbf{3 1}$ & $\mathbf{6 5 \%}$ & $\mathbf{2}$ & $\mathbf{7 \%}$ \\
\hline Both & & & $\mathbf{3}$ & $\mathbf{1 0 \%}$ \\
\hline & $\mathbf{4 8}$ & & $\mathbf{3 0}$ & \\
\hline
\end{tabular}

In terms of practicing the problems, the technology appears to have discouraged a larger percentage of students, $21 \%$ either got discouraged or did not use the study guide as compared to only $6 \%$ in the traditional class. In the high tech class all the problems were online so if the students had trouble with using the web they became effectively foreclosed.

Table 5

\begin{tabular}{|c|c|c|c|c|}
\hline I practiced the problems & \multicolumn{2}{|c|}{ Traditional } & \multicolumn{2}{|c|}{ High Tech } \\
\hline a. all of the assigned problems & 8 & $15 \%$ & 6 & $18 \%$ \\
\hline b. most of the assigned problems & 21 & $40 \%$ & 13 & $39 \%$ \\
\hline c. some of the assigned problems & 21 & $40 \%$ & 7 & $21 \%$ \\
\hline d. tried to, but got discouraged & 1 & $2 \%$ & 4 & $12 \%$ \\
\hline e. did not use the study guide & 2 & $4 \%$ & 3 & $9 \%$ \\
\hline & 53 & & 33 & \\
\hline
\end{tabular}

The traditional classroom model has an active learning exercise that uses the entire class period about once every two weeks. These exercises are generally fun (auctioning off money or conducting a prisoner's dilemma style negotiation) however the lesson derived from the exercise may be less obvious than a more linear presentation of the material. 
Table 6

\begin{tabular}{|l|c|c|c|c|}
\hline I found classroom activities (circle all that apply) & \multicolumn{2}{|c|}{ Traditional } & \multicolumn{2}{c|}{ High Tech } \\
\hline a. Enjoyable & $\mathbf{3 2}$ & $\mathbf{6 3 \%}$ & $\mathbf{1 0}$ & $\mathbf{3 0 \%}$ \\
\hline b. Interesting & $\mathbf{1 0}$ & $\mathbf{2 0 \%}$ & $\mathbf{1 5}$ & $\mathbf{4 5 \%}$ \\
\hline c. Instructional & $\mathbf{6}$ & $\mathbf{1 2 \%}$ & $\mathbf{1 6}$ & $\mathbf{4 8 \%}$ \\
\hline d. Moderately ineffective & 3 & $6 \%$ & 5 & $15 \%$ \\
\hline e. Very ineffective & 0 & $0 \%$ & 0 & $0 \%$ \\
\hline & 51 & & 33 & 3 \\
\hline
\end{tabular}

The greatest area of dissatisfaction is with the textbook. In the traditional course, $50 \%$ found the book ineffective or very ineffective, in the high tech course, $60 \%$ found the book ineffective or very ineffective. Part of this problem may be that some students chose not to purchase a hard copy of the book and therefore had to do their reading online which can be difficult. Note some of the students who found the book ineffective also found it instructional; $42 \%$ of the traditional students and $45 \%$ of the high-tech students found it instructional. In this area, both classroom approaches yield similar results.

Table 7

\begin{tabular}{|l|c|c|c|c|}
\hline I found the textbook (circle all that apply) & \multicolumn{2}{|c|}{ Traditional } & \multicolumn{2}{c|}{ High Tech } \\
\hline a. Enjoyable & 0 & $0 \%$ & 1 & $3 \%$ \\
\hline b. Interesting & 3 & $6 \%$ & 3 & $9 \%$ \\
\hline c. Instructional & $\mathbf{2 0}$ & $\mathbf{4 2 \%}$ & $\mathbf{1 5}$ & $\mathbf{4 5 \%}$ \\
\hline d. Moderately ineffective & $\mathbf{2 0}$ & $\mathbf{4 2 \%}$ & $\mathbf{1 3}$ & $\mathbf{3 9 \%}$ \\
\hline e. Very ineffective & $\mathbf{5}$ & $\mathbf{1 0 \%}$ & $\mathbf{7}$ & $\mathbf{2 1 \%}$ \\
\hline & $\mathbf{4 8}$ & & $\mathbf{3 3}$ & \\
\hline
\end{tabular}

How the students rank the lectures is difficult to analyze. Relative to auctioning off dollar bills, any normal classroom lecture will be duller. On the other hand, in the high tech course, if the online quizzes have compelled the students to read more thoroughly in advance, the lecture/discussion can focus on the more interesting applications and extensions of the lesson rather than conveying the nuts and bolts of the material.

Table 8

\begin{tabular}{|l|c|c|c|c|}
\hline I found the lectures/discussion (circle all that apply) & \multicolumn{2}{|c|}{ Traditional } & \multicolumn{2}{c|}{ High Tech } \\
\hline a. Enjoyable & $\mathbf{1 2}$ & $\mathbf{2 3 \%}$ & $\mathbf{1 4}$ & $\mathbf{4 2 \%}$ \\
\hline b. Interesting & $\mathbf{1 2}$ & $\mathbf{2 3 \%}$ & $\mathbf{1 9}$ & $\mathbf{5 8 \%}$ \\
\hline c. Instructional & $\mathbf{2 4}$ & $\mathbf{4 6 \%}$ & $\mathbf{1 8}$ & $\mathbf{5 5 \%}$ \\
\hline d. Moderately ineffective & $\mathbf{3}$ & $\mathbf{6 \%}$ & $\mathbf{0}$ & $\mathbf{0 \%}$ \\
\hline e. Very ineffective & $\mathbf{1}$ & $\mathbf{2 \%}$ & $\mathbf{2}$ & $\mathbf{6 \%}$ \\
\hline & $\mathbf{5 2}$ & & $\mathbf{3 3}$ & \\
\hline
\end{tabular}

The following table shows similar results for the two approaches: students don't enjoy homework, they don't find it interesting, they do it to learn the material and pass the exams. 
Table 9

\begin{tabular}{|l|c|c|c|c|}
\hline I found homework (circle all that apply) & \multicolumn{2}{|c|}{ Traditional } & \multicolumn{2}{c|}{ High Tech } \\
\hline a. Enjoyable & 0 & $0 \%$ & 0 & $0 \%$ \\
\hline b. Interesting & 5 & $10 \%$ & 4 & $12 \%$ \\
\hline c. Instructional & 37 & $73 \%$ & 19 & $58 \%$ \\
\hline d. Moderately ineffective & 5 & $10 \%$ & 11 & $33 \%$ \\
\hline e. Very ineffective & 4 & $8 \%$ & 4 & $12 \%$ \\
\hline & 51 & & 33 & 3 \\
\hline
\end{tabular}

The high tech model resulted in students on average spending more time studying than in their other courses. In fact $30 \%$ spent much more time and $18 \%$ spent more time. That is nearly half the class spent more time with their economics course than with the other courses they were taking. This is probably attributable to the chapter quiz requirement which forces the students to read the book and answer the questions before class. In the traditional class $50 \%$ of the class spent less or much less time on their economics course. This compares with only $12 \%$ of the high-tech students. Many students don't read the book before class and after the lecture figure that they know it and just skim the material as evidenced by Table 2 above.

Table 10

\begin{tabular}{|l|c|c|c|c|}
\hline $\begin{array}{l}\text { How did this amount compare to the time you spent on your } \\
\text { other courses }\end{array}$ & \multicolumn{2}{|c|}{ Traditional } & \multicolumn{3}{c|}{ High Tech } \\
\hline a. Much more & $\mathbf{1}$ & $\mathbf{2 \%}$ & $\mathbf{1 0}$ & $\mathbf{3 0 \%}$ \\
\hline b. More & $\mathbf{3}$ & $\mathbf{6 \%}$ & $\mathbf{6}$ & $\mathbf{1 8 \%}$ \\
\hline c. About the same & $\mathbf{2 2}$ & $\mathbf{4 2 \%}$ & $\mathbf{1 3}$ & $\mathbf{3 9 \%}$ \\
\hline d. Less & $\mathbf{2 0}$ & $\mathbf{3 8 \%}$ & $\mathbf{3}$ & $\mathbf{9 \%}$ \\
\hline e. Much less & $\mathbf{6}$ & $\mathbf{1 2 \%}$ & $\mathbf{1}$ & $\mathbf{3 \%}$ \\
\hline & $\mathbf{5 2}$ & & $\mathbf{3 3}$ & \\
\hline
\end{tabular}

The effort impact is clearly demonstrated in the table below which asks the students to estimate the average hours per week spent outside of class. The vast majority of traditional students, $63 \%$ of those responding, only spend an average of an hour a week on economics. In the high tech class only $13 \%$ are spending only an hour a week. The traditional class students average 1.8 hours per week while the high tech class students average 5.2 hours per week. In addition to the reading and quizzes, many of the high tech students spent time on the various practice problems and graphs developed specifically for the course which matched the exam questions they would answer on their in class exams.

\section{Table 11}

\begin{tabular}{|c|c|c|}
\hline $\begin{array}{l}\text { On average how many hours per week Outside of class did you } \\
\text { spend reading and studying economics? }\end{array}$ & Traditional & High Tech \\
\hline 1 Hour & 24 & 4 \\
\hline$\underline{2 \text { Hour }}$ & & 5 \\
\hline 3 Hours & 8 & 4 \\
\hline 4 Hours & 5 & 4 \\
\hline$\overline{\text { 5 Hours }}$ & & 3 \\
\hline 6 Hours & 1 & \\
\hline 8 Hours & & 1 \\
\hline$\overline{10 \text { Hours }}$ & & 5 \\
\hline 11 or more Hours (averaged as 12 hours) & & 3 \\
\hline Class average & $\mathbf{1 . 8}$ & 5.2 \\
\hline
\end{tabular}


Student assessment of their learning in the course showed large differences between the high tech class and the traditional class. Specifically in the high tech class $15 \%$ said that they learned much more than in their other courses compared to $4 \%$ in the traditional class. Additionally in the high tech class, $30 \%$ said that they learned more than in their other courses as compared to only $12 \%$ in the traditional class.

Table 12

\begin{tabular}{|l|c|c|c|c|}
\hline $\begin{array}{l}\text { In reflecting on what you learned how would you compare it to } \\
\text { how much you learned in your other courses. (circle one } \\
\text { answer) }\end{array}$ & \multicolumn{2}{|c|}{ Traditional } & \multicolumn{2}{c|}{ High Tech } \\
\hline a. Much more & $\mathbf{2}$ & $\mathbf{4 \%}$ & $\mathbf{5}$ & $\mathbf{1 5 \%}$ \\
\hline b. More & $\mathbf{6}$ & $\mathbf{1 2 \%}$ & $\mathbf{1 0}$ & $\mathbf{3 0 \%}$ \\
\hline c. About the same & $\mathbf{3 0}$ & $\mathbf{5 8 \%}$ & $\mathbf{1 1}$ & $\mathbf{3 3 \%}$ \\
\hline d. Less & 12 & $23 \%$ & 4 & $12 \%$ \\
\hline e. Much less & 2 & $4 \%$ & 3 & $9 \%$ \\
\hline & $\mathbf{5 2}$ & & $\mathbf{3 3}$ & \\
\hline
\end{tabular}

One of the problems with the high tech class is that some students are put off by the technology and don't get help. This problem is evidenced by the responses below regarding the study guide. In the traditional class, students could just open the book. When the study guide is available online, the students have to access the web and then locate the correct material within the website. As we can see $27 \%$ of the students did not find the material on the web or got discouraged using it; only $6 \%$ did all the assigned chapters. In the traditional class, $55 \%$ did the study guide for all the assigned chapters. Aside from technological trepidation, a reason these number might be so different is that in the traditional class, the study guide is the assigned homework, whereas in the high tech class the reading and the quizzes were the assigned work; the study guide and other exercises were available options to use to study for exams. Students tend to do work that is specifically assigned and graded.

Table 13

\begin{tabular}{|l|c|c|c|c|}
\hline Did you use any of the study guide? (circle one answer) & \multicolumn{2}{|c|}{ Traditional } & \multicolumn{2}{c|}{ High Tech } \\
\hline a. For all of the assigned chapters & $\mathbf{2 8}$ & $\mathbf{5 5 \%}$ & $\mathbf{2}$ & $\mathbf{6 \%}$ \\
\hline b. For most of the assigned chapters & $\mathbf{1 5}$ & $\mathbf{2 9 \%}$ & $\mathbf{6}$ & $\mathbf{1 8 \%}$ \\
\hline c. For some of the assigned chapters & $\mathbf{7}$ & $\mathbf{1 4 \%}$ & $\mathbf{1 6}$ & $\mathbf{4 8 \%}$ \\
\hline d. Tried to use them but got discouraged & 0 & $0 \%$ & 4 & $12 \%$ \\
\hline e. Did not find them on the web & 1 & $2 \%$ & 5 & $15 \%$ \\
\hline & 51 & & 33 & \\
\hline
\end{tabular}

Table 14

\begin{tabular}{|l|c|c|c|c|}
\hline I found the study guide (circle all that apply) & \multicolumn{2}{|c|}{ Traditional } & \multicolumn{2}{c|}{ High Tech } \\
\hline a. Enjoyable & 4 & $8 \%$ & 1 & $3 \%$ \\
\hline b. Interesting & 7 & $14 \%$ & 3 & $9 \%$ \\
\hline c. Instructional & $\mathbf{3 8}$ & $\mathbf{7 6 \%}$ & $\mathbf{2 3}$ & $\mathbf{7 0 \%}$ \\
\hline d. Moderately ineffective & 1 & $2 \%$ & 5 & $15 \%$ \\
\hline e. Very ineffective & 4 & $8 \%$ & 0 & $0 \%$ \\
\hline & 50 & & 33 & \\
\hline
\end{tabular}

\section{Assessment of Digital Teaching Tools - Survey Results:}

Web-based assignments were created by Dr. Granitz, co-author of this paper; these assignments are introduced in the two courses to identify the importance of context, that is, the importance of the overall pedagogical 
approach in the introduction of an innovative teaching tool. Digital graphs were created to depict various industry structures: perfect competition, monopolistic competition and monopoly in both the long run and short run. The high tech students had these digital graphs imbedded with the other online materials. The traditional students were emailed the set of digital graphs. While the majority of students in the traditional class had problems with using the digital graphs, many did try and did use them. Some students in the high tech class were also challenged by the digital format and only $12 \%$ used all of them. Of the students who used the online material throughout the semester $78 \%$ did some, most, or all of the web exercises. Of the traditional class, $47 \%$ used them to some extent.

Table 15

\begin{tabular}{|l|c|c|c|c|}
\hline I did the digital exercises (the graphs I e-mailed you) & \multicolumn{2}{|c|}{ Traditional } & \multicolumn{2}{c|}{ High Tech } \\
\hline a. all of the web exercises & $\mathbf{6}$ & $\mathbf{1 2 \%}$ & $\mathbf{3}$ & $\mathbf{9 \%}$ \\
\hline b. most of the web exercises & $\mathbf{5}$ & $\mathbf{1 0 \%}$ & $\mathbf{1 4}$ & $\mathbf{4 2 \%}$ \\
\hline c. some of the web exercises & $\mathbf{1 3}$ & $\mathbf{2 5 \%}$ & $\mathbf{9}$ & $\mathbf{2 7 \%}$ \\
\hline d. tried but got discouraged & 8 & $16 \%$ & 4 & $12 \%$ \\
\hline e. did not use the web exercises & 19 & $37 \%$ & 3 & $9 \%$ \\
\hline & 51 & & 33 & \\
\hline
\end{tabular}

Almost half of the high tech students, who had digital material all semester, felt that the digital graphs helped them participate more in class and perform better on tests whereas about a third of the traditional students had that response.

Table 16

\begin{tabular}{|l|c|c|c|c|c|c|c|c|}
\hline & \multicolumn{3}{|c|}{ Traditional High Tech } \\
\hline & Yes & No & Yes & No & Yes & No & Yes & No \\
\hline $\begin{array}{l}\text { Do you believe the digital material helped you to } \\
\text { participate more in class? }\end{array}$ & 17 & 34 & $33 \%$ & $67 \%$ & 15 & 18 & $45 \%$ & $55 \%$ \\
\hline $\begin{array}{l}\text { Do you believe the digital material helped you } \\
\text { perform better on tests? }\end{array}$ & 18 & 33 & $35 \%$ & $65 \%$ & 16 & 17 & $48 \%$ & $52 \%$ \\
\hline
\end{tabular}

In the high tech class the vast majority of the students (70\%) found the digital graphs instructional. $21 \%$ of the high tech students did not use them or got discouraged (Table 15, above); this means that of the students who used them, $85 \%$ found them instructional, and some of those also found them interesting and enjoyable. While half of the traditional students found the web exercises instructional, a larger proportion found them ineffectual. This is to be expected. When one introduces a pedagogy that is less familiar, it is less well received, regardless of the value of the pedagogy. Just as collaborative work is better received when done consistently throughout the semester, high tech exercises will be more effective if integrated throughout the course. It should be that $66 \%$ of the traditional students who used the graphs found them instructional, 24 traditional students used the digital graphs (Table 15 above) 16 found them instructional (Table 17. below).

Table 17

\begin{tabular}{|l|c|c|c|c|}
\hline I found the digital graphs (circle all that apply) & \multicolumn{2}{|c|}{ Traditional } & \multicolumn{2}{c|}{ High Tech } \\
\hline a. Enjoyable & $\mathbf{2}$ & $\mathbf{6 \%}$ & $\mathbf{4}$ & $\mathbf{1 2 \%}$ \\
\hline b. Interesting & $\mathbf{7}$ & $\mathbf{2 2 \%}$ & $\mathbf{6}$ & $\mathbf{1 8 \%}$ \\
\hline c. Instructional & $\mathbf{1 6}$ & $\mathbf{5 0 \%}$ & $\mathbf{2 3}$ & $\mathbf{7 0 \%}$ \\
\hline d. Moderately ineffective & $\mathbf{9}$ & $\mathbf{2 8 \%}$ & $\mathbf{2}$ & $\mathbf{6 \%}$ \\
\hline e. very ineffective & $\mathbf{1 0}$ & $\mathbf{3 1 \%}$ & $\mathbf{2}$ & $\mathbf{6 \%}$ \\
\hline & $\mathbf{3 2}$ & & $\mathbf{3 3}$ & \\
\hline
\end{tabular}


In both courses many of the students who did use the digital graphs found them helpful or very helpful. In the high tech class only $10 \%$ found them unhelpful or a waste of time compared to $38 \%$ in the traditional class, again in analyzing these results we should remember that only 24 students said they used the graphs.

\section{Table 18}

\begin{tabular}{|l|c|c|c|c|}
\hline I found the digital graphs (circle all that apply) & \multicolumn{2}{|c|}{ Traditional } & \multicolumn{2}{c|}{ High Tech } \\
\hline a. Very helpful & $\mathbf{1}$ & $\mathbf{2 \%}$ & $\mathbf{1 0}$ & $\mathbf{3 4 \%}$ \\
\hline b. Helpful & $\mathbf{1 7}$ & $\mathbf{3 5 \%}$ & $\mathbf{7}$ & $\mathbf{2 4 \%}$ \\
\hline c. Neutral & $\mathbf{1 2}$ & $\mathbf{2 5 \%}$ & $\mathbf{9}$ & $\mathbf{3 1 \%}$ \\
\hline d. Unhelpful & 12 & $25 \%$ & 2 & $7 \%$ \\
\hline e. A waste of time & 6 & $13 \%$ & 1 & $3 \%$ \\
\hline & 48 & & 29 & \\
\hline
\end{tabular}

\section{Assessment of Survey Results - Conditioned on Student Effort}

We take into consideration the amount of effort expended by the student. First we look at the answers of those who actually read the book. Of the high tech students, 50\% think it helped them on tests and 30\% thought it enhanced classroom participation, this differs from the entire high tech class perception where $26 \%$ thought it would help with tests and $44 \%$ thought it would help classroom participation. So apparently those who didn't read the book thought it wouldn't help much and more of those who did read the book found it useful. In the traditional setting, of those who read the book, $30 \%$ did so to help prepare for the test while over 50\% did so to prepare for class. Again these numbers are slightly higher that the entire class, so those who read the book confirm that it is useful.

The differences shown below between the two classroom environments show that the high tech students are motivated by the desire to do well on the tests.

Figure 1

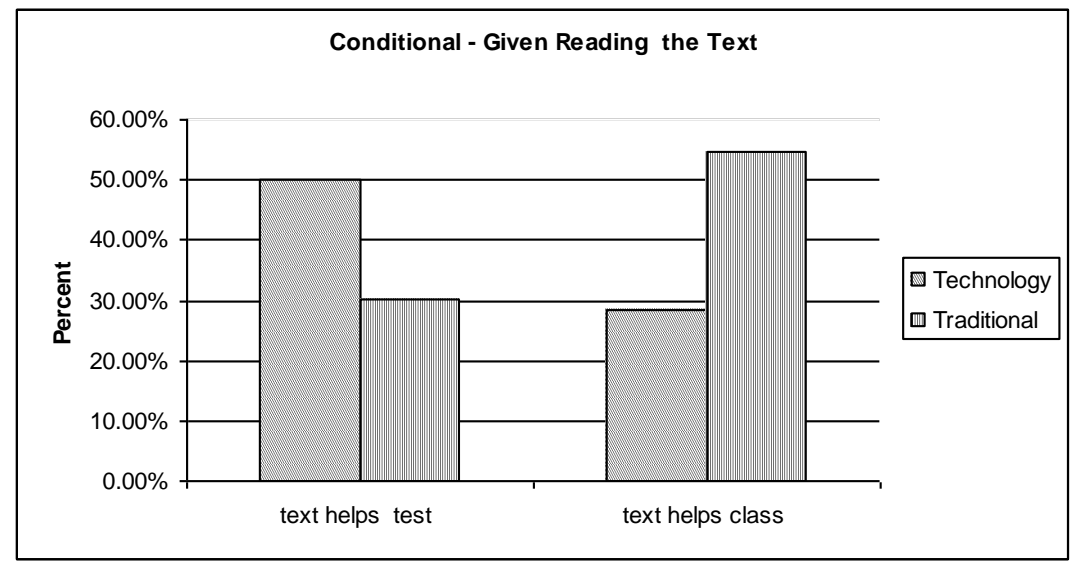

Next we assess student effort by the amount of time the students devote to this course relative to other courses; they may spend more time on this course, relative to others, the same amount, or less time than others. If they spend more time, do they perceive that they get more out of it? 
Figure 2

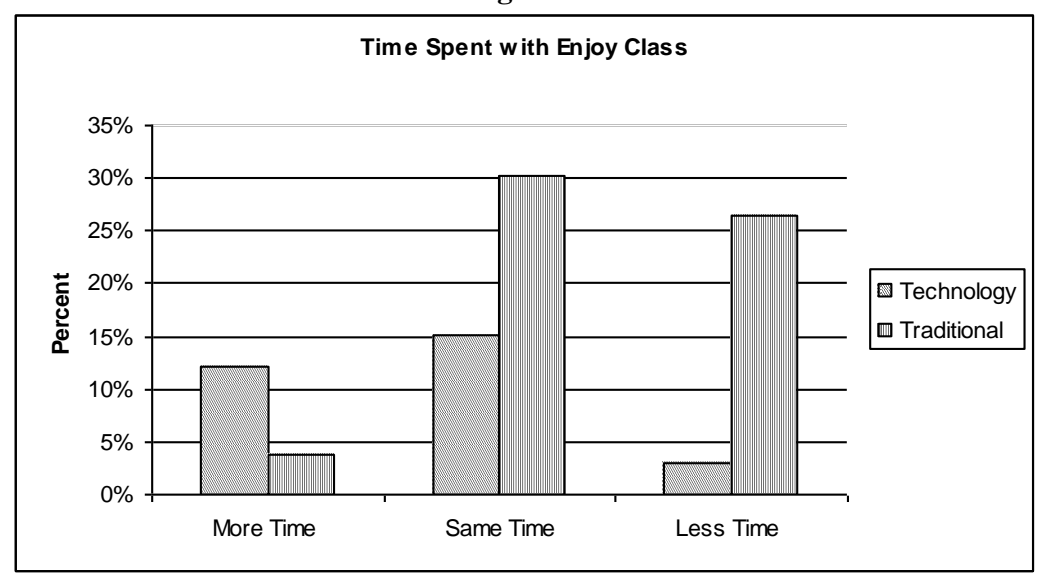

Figure 3

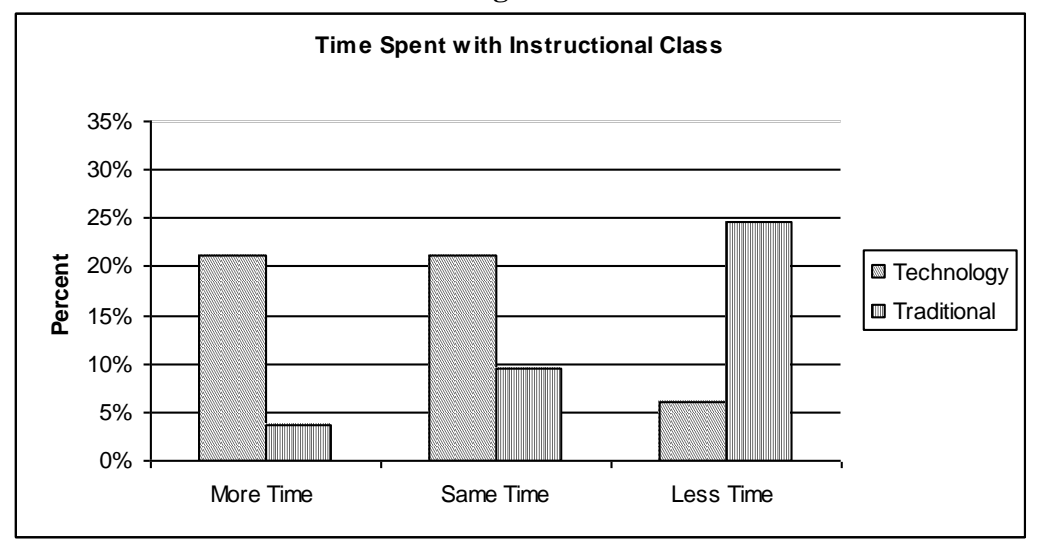

Figure 4

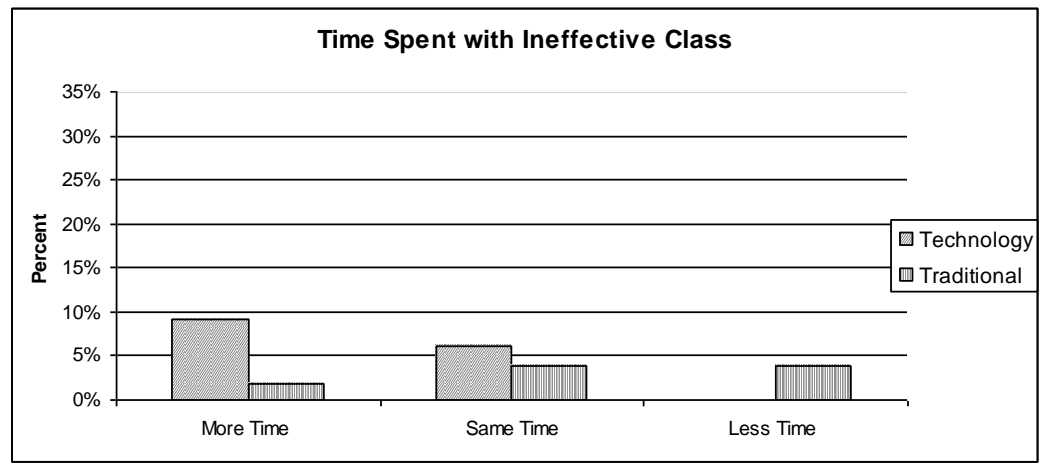

Looking at the students that spend more time in their high tech course than in others, about $12 \%$ found it enjoyable, just over $20 \%$ found it instructional and fewer than $10 \%$ found it ineffectual. There were fewer students in the traditional course that spent more time in this course, resulting in numbers less than $5 \%$ in each case. In both sets of classes, about $40 \%$ of the students spent the same amount of time preparing for microeconomics, the traditional students enjoyed it more and the high tech found it more instructional. Of the students that spent less time 
on this course, there were very few high tech students and the percentages hover around 5\% in each case. The traditional students who spent little time were able to enjoy class (25\%) and found it instructional (20\%). This last difference highlights the fact that the high tech students had to prepare whereas the traditional students were able to get something out of class despite inadequate preparation.

\section{Conclusions From The Survey:}

The survey shows that using a variety of online tools and online chapter quizzes can increase the amount of time devoted to a course, and the perceived learning in introductory economics. The caveat is that one can not simply introduce high tech exercises ad hoc. They are most effective when couched in an ongoing high tech learning environment. This effectiveness will of course be compromised if the students are uncomfortable with the high tech learning environment. The drop rate for the high tech course this year is $25 \%$; this may be due to the technology or perceptions that the instructor is more demanding than others. The traditional class had zero drops. This may be due to the fact that the course activities are engaging or because the instructor teaches most of the microeconomics classes and there are few alternatives!

\section{CONCLUSIONS}

From the instructor's point of view, once the quizzes are set up and any additional material is developed, most of it can be reused for several years as these are basic microeconomic concepts. The graded online quiz encourages the students to engage the material prior to class and does not take any time away from lecture nor does it require any time to grade. The grades are automatically recorded in the student grade book. So the cost of set up is there, but it can be spread over many semesters and the ongoing costs are minimal. This entire process has gotten much easier for instructors over the past few years as more and more publishers are creating good online tools to complement either a hardcopy book or an online book. The benefit is that the students come to class with a better idea of the basic concepts in each chapter and so more time can be spent evaluating the models and discussing the insights these models provide about the world. This provides the opportunity to have more of a discussion/dialogue or a collaborative learning format rather than straight lecture. The graded quizzes provide immediate feedback to both the student and instructor; the instructor can review the quiz results and determine which concepts a large number of students did not understand. Another advantage of the online quiz is that it forces the students to go online and once there they may try some of the other online tools. In courses where there is no compelling reason to go online, students tend to ignore the supplemental material there.

Innovative pedagogy, whether through active learning exercises or online material is needed to reach a more diversified student body, accommodating various learning styles. It is more is stimulating and a stimulating environment is conducive to learning. We are making efforts to extend the student's learning experience and this is our initial attempt to assess the impact of the various tools in two different environments.

\section{AUTHOR INFORMATION}

Susan Christoffersen, Ph.D. associate professor of economics, School of Business Administration, earned her Ph.D. in Economics, NYU, 1990. Her earliest theoretical work focuses on international issues: innovation races: impact of research/development subsidies; published in: Journal of Global Competitiveness and Applied Business Research. Textile/apparel industries provide an area in which this theoretical work is applied, publications in Empirical Economics, Journal of Business and Economic Studies. First member of the School of Business to garner prestigious Nat'l Textile Center multiyear grant. Her pedagogical work appears in: American Economist, Journal of Financial Education, Journal of Business, and the Journal of Educational Leadership. Elected: board of Eastern Economics Association (twice), Am. Assoc. of Economic and Financial Experts, and serves as referee for various journals. Her presentation at the HK Federation won one of six global Outstanding Initiative Awards for businessuniversity outreach training/dissemination, based on work for a grant form the US Dept of Education.

Elizabeth Granitz earned her BA in Economics from Cornell University and her Ph.D. from the University of California at Los Angeles. She is currently an Associate Professor of Economics at the C.W. Post Campus of Long Island University. In 1994 Granitz earned the David Newton Teaching Award. She is an active participant in the Teaching with Technology Institute for the past five years and a member of the L.I.U. Web-Mediated Instruction 
Taskforce. Granitz developed a number of successful economics learning objects and integrated them with commercially available web-based tools to enhance the educational experience of her students.

\section{REFERENCES}

1. Becker, W.E. and M. Watts. 1996. Chalk and talk: A national survey on teaching undergraduate economics. American Economic Review Proceedings 86 (May): 448-53.

2. Boyle, T., Bradley, C., Chalk, P., Jones \& Pickard, P. (2003, October). Using blended learning to improve student success rates in learning to program. Journal of Educational Media, 28(2-3), 165-178

3. Buckles, S. 2001. Evidence from Learning Theory: The Need for a New Introductory Course. Presented at the Eastern Economics Association Meetings. February 23, 2001.

4. Buckles, S. 1998. "Using Cases as an Effective Active Learning Technique". In Teaching Economics to Undergraduates: Alternatives to Chalk and Talk. W.E. Becker and M.Watts, eds. Northampton, MA: Edward Elgar.

5. $\quad$ Cross, P.K. 1987. Teaching for learning. AAHE Bulletin 39 (April): 2-7.

6. Graff, Martin, (2003). Learning from web-based instructional systems and cognitive style. British Journal of Education Technology, 34(4), 407-418.

7. Hansen, W.L., M.K. Salemi, and J.J. Siegfried. 2001. Creating a Standards-Based Economics Principles Course. Presented at the Eastern Economics Association Meetings. February 23, 2001.

8. Hung, D. (2001). Theories of learning and computer-mediated instructional strategies. Education Media International, 38(4), 281-287.

9. Johnson, D.W., R.T. Johnson, and K.A. Smith. 1991. Active Learning: Cooperation in the college classroom. Edina, MN: Interaction Book Company.

10. Lage, M.J. and M. Treglia. 1998. "Gender and Active Learning”. In Teaching Economics to Undergraduates: Alternatives to Chalk and Talk. W.E. Becker and M.Watts, eds. Northampton, MA: Edward Elgar.

11. Laster, S. (2005). Model driven design: Systematically building blended learning experiences. In J. Bourne \& J. Moore (Eds.), Elements of quality online education: into the mainstream (pp. 159-175). Needham, MA: Sloan C.

12. Light, R.J. 1990. The Harvard Assessment Seminars: Explorations with students and faculty about teaching, learning, and student life. Cambridge: Harvard University Graduate School of Education.

13. Lohr, L.L. \& Ku, H. (2003). Development of a web-based template for active learning, The Quarterly Review of Distance Education, 4(3), 213-226.

14. MacDonald, J., \& McAteer, E. (2003). New approaches to supporting students: strategies for blended learning in distance and campus based environments. Journal of Educational Media, 28(2-3), 129-146.

15. Newby, Timothy J., Donald A. Stepich, James D. Lahman, James D. Russell. (2000) Instructional Technology for Teaching and Learning: designing instruction, integrating computers, and using media, $2^{\text {nd }}$ Edition. Upper Saddle River, New Jersey: Merrill Prentice Hall.

16. Reasons, S., Valadares, K., \& Slavkin, M. (2005). Questioning the hybrid model: Student outcomes in different course formats. Journal of Asynchronous Learning, 9(1), 83-94.

17. Rogers, D.L., 2000. "A Paradigm Shift: Technology Integration for Higher Education in the New Millenium." Educational Technology Review.( Spring/Summer ): 12-33.

18. Schroeder, R. \& Oakley, B. (2005). Adding clicks to bricks: Increasing access to mainstream education. In J. Bourne \& J. Moore (Eds.), Elements of quality online education: Engaging communities (pp. 101115). Needham, MA: Sloan-C.

19. Shea, P.J., Swan, K., Fredericksen, E. E., \& Pickett, A. (2001). Student satisfaction as reported learning in the SUNY learning network. Elements of quality online education, 3 (pp. 145-156). Needham, MA: Sloan-C.

20. Siegfried, J.J., R.L. Bartlett, W.L. Hansen, A.C. Kelley, D.N. McClosky, and T.H. Tietenberg. 1991. The status and prospects of the economics major. Journal of Economic Education 22 (Summer): 197-224.

21. Starenko M., Vignare, K., \& Humbert, J. 9In press). Enhancing student interaction and sustaining faculty instructional innovations through blended learning. In A. Picciano \& C. Dziuban (Eds.), Blended Learning. Needham, MA: Sloan-C.

22. Vail, P. 1994. Emotion: the On/Off Switch for Learning. Rosemont, N.J: Modern Learning Press. 